\title{
Avrupa Konseyi Biyoetik Komitesi'nin Psikiyatriye İlişkin Ek Protokol Çalışması Neler Söylüyor?
}

\author{
What Does The Council of Europe Committee on Bioethics's Additional Protocol for Psychiatry Study Say?
}

Ankara Üniversitesi Tip Fakültesi Tip Tarihi ve Etik Anabilim Dalı, Ankara, Türkiye

Correspondence:

Abdullah YILDIZ

Ankara Üniversitesi Tip Fakültesi Tip Tarihi ve Etik Anabilim Dal, Ankara,Türkiye

e-mail:

dr.abdullahyildiz@hotmail.com
Abdullah Yıldız, Ayşe Kurtoğlu, Berna Arda, Özet

Psikiyatrik sorunlara ve psikiyatri pratiğine ilişkin etik duyarlllı örneklerini Dünya Psikiyatri Birliğịnin bildirgelerinde, ulusal hekim birliklerinin etik kodlarında ve uzmanlık derneklerinin konuya ilişkin metinlerinde görmek mümkündür. Bu bağlamda Türkiye Psikiyatri Derneğinin ilke olarak benimsediği, "bilim, etik, dayanışma" söylemini ve 2002 yllında kapsamlı bir biçimde ortaya koyduğu "Ruh Hekimliği (Psikiyatri) Meslek Etiği Kuralları”n görmek mümkündür. Bu çalışmada ülkemizin iç hukukunu biyoetik bağlamında "İnsan Hakları ve Biyotıp Sözleșmesi” ile etkilemiş olan Avrupa Konseyi’nin Biyoetik Komitesỉnin psikiyatriye ilişkin ek protokol çalışmalarının ortaya konulması ve tartışılması amaçlanmışıı. Protokol çalışmaları Biyoetik Komitesi tarafından yürütülmektedir. Süreç, hasta ve yakınlarının, hekimlerin ve ilgili diğer sağlık çalışanları ile insan hakları derneklerinin görüslerinin alınarak ek protokol olusturulması için organize edilmistir. Ayrıca kamuoyu görüslerinin alınması da önemsenmektedir. Protokolün üzerinde durduğu öncelikli konuların başında ülkelerin yasal düzenlemelerinde boşluklar olduğu görülen istem dışı yatı̧s ve tedavi konusu yer almaktadır. Taslak protokolde istem dıșı yatı̧ ve tedavi kavramlarının, bunlara konu olan kişilerin durumunun, istem dışı yatış sürecinde değerlendirici olarak psikiyatristler ve yetkinlikleri konularının ayrıntılı șekilde ele alındığı görülmektedir. Ülkemizde henüz yasalaşmamış olsa da Türkiye Psikiyatri Derneğinnin önemli düzeyde katkı sunduğu "Ruh Sağlığı Yasası Taslağı" ile "Ruh Hekimliği (Psikiyatri) Meslek Etiği Kuralları" içerisinde konunun ayrıntılı biçimde yer almış olduğu dikkate değerdir.

Anahtar kelimeler: Psikiyatri etiği; biyoetik; Avrupa Konseyi

\section{Abstract}

Examples for Ethical sensitivity in the psychiatric problems and psychiatric practice can be found in the declarations of the World Psychiatric Association, ethical codes of national physician associations, and expert associations' texts about the issue. It is possible to conceive the practices of the Psychiatric Association of Turkey such as issuing "Psychiatry Rules of Occupational Ethics" in 2002 and accepting "science, ethics, solidarity" discourse as a principle within this context. This study aimed to present and discuss the Council of Europe Committee on Bioethis's additional protocol for psychiatry studies that influenced the internal law of our country with the "Convention on Human Rights and Biomedicine" within the context of bioethics. Protocol studies are carried out by the Committee on Bioethics. The process is organized to establish an Additional Protocol by taking the opinions of patients and relatives, physicians, other healthcare professionals, and human rights associations. Opinions of the public about the issue are also deemed important. Involuntary placement and treatment, about which there are legal gaps, is the leading important issue on which the protocol focused.In the draft protocol, involuntary placement and treatment concepts, the status of persons subject to these concepts, psychiatrists and competencies as evaluators during involuntary hospitalization are addressed elaborately. Although it has not yet been legalized in Turkey, it is worth noting the issue addressed in "Mental Health Act Draft" and "Rules of Occupational Ethics of Psychiatry" to which the Psychiatric Association of Turkey contributed to significantly. Keywords: Psychiatric ethics; bioethics; Council of Europe 


\section{Giriş}

Tıp, etik duyarlılığın geçmişinin oldukça eskiye dayandığı mesleklerin başında gelmektedir. Genel olarak eski çağlardan itibaren hekimlerin kendilerine kurallar koyduğunu görmek mümkündür; bunun en bilinen kanıtlarına hekim antlarında rastlanmaktadır. Bir tıp dalı olarak psikiyatri, gerek hasta-hekim ilişkisinin özellikli yapısı bakımından gerekse de uğraşısının doğasına bağlı olarak toplum, hasta ve hekim üçgeninde zorlayıcı etik kararların alınabildiği, zaman zaman da tartışmalı konuların gündeme geldiği alanlardan biridir.

Psikiyatrik sorunlara ve psikiyatri pratiğine ilişkin etik duyarlılık örneklerini Dünya Hekimler Birliği'nin (WMA) çeşitli bildirgelerinde, özellikle Dünya Psikiyatri Birliği'nin Hawaii ile Madrid Bildirgelerinde, ulusal hekim birliklerinin etik kodlarında ve uzmanlık derneklerinin konuya ilişkin metinlerinde görmek mümkündür. $\mathrm{Bu}$ bağlamda, Türkiye Psikiyatri Derneği'nin (TPD) ilke olarak benimsediği, "bilim, etik, dayanışma" söylemini ve 2002 yılında oldukça kapsamlı bir biçimde ortaya koyduğu "Ruh Hekimliği (Psikiyatri) Meslek Etiği Kuralları" ülkemizde psikiyatri pratiği açısından belirleyici role sahiptir $(1,2)$. Üyesi olduğumuz Avrupa Konseyi ise genel olarak insanlı onuru ve insan haklarının korunmasını önemli bir öncelik alanı olarak kabul etmiştir. Konsey'in 4 Nisan 1997 tarihinde imzaya açtığ 1 ve biyoetik alanında standartlar sağlama açısından en önemli belgelerden biri olarak kabul edilen Biyoloji ve Tibbın Uygulanması Bakımından İnsan Hakları ve İnsan Haysiyetinin Korunması Sözleşmesi: İnsan Hakları ve Biyotıp Sözleşmesi (Oviedo Sözleşmesi)'nin en önemli özelliklerinden biri, ek protokoller aracılığıyla gelişime ve dönüşüme açık olan yapısı ve salt etik kodları aşarak biyoetik ile hukuk arasında adeta bir köprü görevi görmesidir (4,5). 2003 y1lında 5013 kanun sayısıyla ülkemiz tarafindan onaylanan ve 2004 yılında yürürlüğe giren Sözleşme'nin 7. maddesi, özel olarak ruhsal sorun yaşayan bireyleri ilgilendirmektedir (3).
$\mathrm{Bu}$ çalışmada daha önce ülkemizin iç hukukunu özellikle biyoetik bağlamında "İnsan Hakları ve Biyotıp Sözleşmesi" ile etkilemiş olan Avrupa Konseyi'nin Biyoetik Komitesi (DH-BIO)'nin psikiyatriye ilişkin ek protokol çalışmalarının ortaya konulması ve tartışılması amaçlanmıştır. $\mathrm{Bu}$ protokol "Ruhsal Rahatsızlığı Olan Bireylerin İstem Dışı Yatış ve İstem Dışı Tedavisine İlişkin İnsan Hakları ve Onurunun Korunması Hakkında Ek Protokol (Additional Protocol concerning the protection of human rights and dignity of persons with mental disorder with regard to involuntary placement and involuntary treatment)" adını taşımaktadır. Bu protokolün oluşturulma kararındaki rasyonel, konunun özellikli bir konu olması ve üye ülkelerin iç hukuklarında konuya ilişkin düzenlemelere ilişkin eksikliklerin görülmüş olmasidır (3). $\mathrm{Bu}$ bağlamda protokol çalışmalarına başlanmıştır. Uzun ve kapsamlı sayılabilecek taslak çalışmaları son aşamalarına yaklaşmış olup Konsey onayına sunulması beklenmektedir. Etik bildirgeler ile ek protokol arasındaki en temel fark, yasal yönden yaptırım potansiyelleridir. Bu açıdan gerek İnsan Hakları ve Biyotıp Sözleşmesi gerekse de onun ek protokoller ile genişleyen etki alanının hem etiği hem hukuku ilgilendirdiğini ifade etmek olanaklıdır. Ek Protokol kabul edilip ülkemiz tarafindan da onaylandığ 1 takdirde psikiyatri etiği ve iç hukukumuz açısından etkin bir metin olacağ 1 düşünülmektedir. Ek Protokolün ortaya konulmasından önce, kısaca Dünya Psikiyatri Birliği tarafından ortaya konulmuş psikiyatri etiğine ilişkin bildirgeler hakkında da bilgi verilmesi planlanmıştır. Sonrasında ülkemiz için önemli metinler olan Ruh Hekimliği (Psikiyatri) Meslek Etiği Kuralları ve Ruh Sağlığı Yasası Taslağı'ndan kısaca bahsedilecek ve ek protokol çalışmaları konusu ele alınacaktır. 


\section{Dünya Psikiyatri Birliği Bildirgeleri: Hawaii ve Madrid Bildirgeleri}

Tıp etiği açısından psikiyatriye ilişkin düzenlemelerin en spesifik olanlarının Hawaii ve Madrid Bildirgeleri olduğunu söylemek mümkündür. Hawaii Bildirgesi’nin arka planına bakıldığında, konumuzun esasını temsil eden psikiyatriye ilişkin ek protokolle benzer bir konu alanına yönelik kaygılardan doğduğu anlaşılmaktadır. Bir yönüyle bu Bildirge özellikle bazı ülkelerde psikiyatrinin politik amaçlarla kötüye kullanılmasına, bazı politik rakiplerin psikiyatrik hastalıkları olduğu iddiası ile zorla yatırılmasına bir tepkidir. 1977 'de Dünya Psikiyatri Kongresi'nde kabul edilen Bildirge, genel anlamda psikiyatrinin politik kullanımına bir reddiye niteliği taşımakta ve psikiyatristlerin psikiyatri ve hekimlik etiği ilkelerini öncelemelerini vurgulamaktadır (4-6).

Bildirgede bilimsel ve etik gerekçelerle uyumlu olarak gerekli durumlarda zorla yatırma ve tedavilerden bahsedilirken, mümkün olduğunca hasta ve/veya yakınlarının onamı ile hastanın üstün yararı ve onuruna ağırlı verilmesine gönderme yapılmaktadır. Yine, eğer hasta gönüllü olarak tedaviyi yatarak sürdürmek istemez ise zorla yatış koşulları ortadan kalkar kalkmaz hastanın taburculuğunun yapılması gereğine vurgu yapılmaktadır. Bu süreçlerin tarafsız ve bağımsız kişilerce yürütülmesi ve denetlenmesine de göndermede bulunulmakta, ayrıca hastaların yakınları dışında temsilcilerinin de sürece dahil edilmesinin teşvik edilmesi önerilmektedir. Özellikle bireysel olarak psikiyatristlerin profesyonel bilgilerini kişi veya gruplara yönelik kötüye kullanmamaları, tedavilerini olumsuz etkileyecek kişisel arzu ve önyargılara izin vermemeleri belirtilmiştir. Bildirgeye göre, gerçek bir psikiyatrik tablo ve bu bağlamda hastanın yararı olmaksızın asla üçüncü tarafların 1srarı ile zorla tedavi ve yatırma gibi işlemlerde yer alınmamalı ve bu talepler reddedilmelidir (4-6).

Hastanın terapötik süreçte getirdiği bilgilerin gizliliği konusu da bir diğer önemli konu olarak Hawaii Bildirgesi'nde yer almıştır. Bilimsel psikiyatrik bilginin gelişimi açısından hastaların katılımının önemine değinilirken, hastaların onamlarının aranması önemli bir gereklilik olarak deklare edilmiş ve araştırma etiği ilkelerine uyulmasına, hastaların tedavilerinin aksamaması gibi konulara dikkat çekilmiştir (6). Şüphesiz zaman akıp toplumsal yap1 değişirken, bilimsel bilgi ve uygulamalar da gelişmekte ve değişmektedir. Bu durum da kaçınılmaz olarak yeni sorunlar ve çözüm arayışlarını gündeme getirmektedir.

Genel olarak Hawaii Bildirgesi, daha sonra Dünya Psikiyatri Birliği tarafından yayınlanan etik kodlar ve bildirgeler için temel bir zemin oluşturmaktadır. Süreç içinde Madrid Bildirgesi'nin ortaya çıkmasına gereksinim duyulmuştur (4).

Dünya Psikiyatri Birliği’nin 1977'de Hawaii Bildirgesi ile başlayan etik standartlar koyma çabası, zaman içinde sosyal ve kültürel değişikliklerle birlikte psikiyatri ve tıp pratiğindeki değişikliklerin dinamik yapısına paralel olarak yeni ve kapsamlı çalışmaları gerekli kılmıştır (4,7). Bu bağlamda 1996 y1lında düzenlenen genel kurul toplantısında Madrid Bildirgesi kabul edilmiş ve zaman içinde de değişikliklerle gelişimini sürdürmüştür. Son değişiklikler 2011 yılında Arjantin'de gerçekleştirilen toplantıda yapılmıştır. Madrid Bildirgesi'nin kapsamının Hawaii Bildirgesi'ne oranla oldukça geniş olduğunu söylemek mümkündür (7). Bildirge'nin üzerine yükseldiği temel söylem; psikiyatristlerin sürekli bir biçimde hekimhasta ilişkisinin sınırlarına dikkat etmeleri gereği ve hastaların kişisel bütünlük ve iyilik hallerini merkeze alan bir sorumluluk bilincinin rehberliğine başvurmaları gerektiğidir. Madrid Bildirgesi bu temel felsefe üzerinden etik standartlar koyma amacı taşımaktadır. Bu bağlamda 7 temel etik standardın yanı sıra özelleşmiş 16 alt başlık ile psikiyatristlere rehberlik edilmesi amaçlanmıştır.

Temel etik standartlar özetle: toplumun ruh sağılığını korumak ve en iyi psikiyatrik hizmeti sunmak; bilimsel gelişmelere ve bilimsel bilgiye dayalı bir psikiyatrik hizmet sunumu; hastaların terapötik süreçte sürecin önemli bir parçası ve partneri olarak kabul görmeleri gereği ve kurulacak güven ilişkisinin önemi; ağır psikiyatrik tablolar ve 
yeterliğin kaybedildiği durumlarda hastanın üstün yararının gözetilmesi koşuluyla sürecin hasta yakınlarının bilgisi dahilinde ve yasal hakların gözetilerek sürdürülmesi; bireylere ilişkin üçüncü tarafların taleplerine dayanan değerlendirme süreçlerinde de değerlendirilen bireyin sürece ilişkin uygun biçimde bilgilendirilmesi gereği; hastayla terapötik süreç içinde ortaya çıkan bilgilerin gizliliği ve güven ilişkisine özen gösterilmesi, bu bilginin ancak hasta yararı ve izniyle/onayına başvurularak açıklanabilir oluşu ya da başkalarına yönelmiş bir tehdit içermesi; araştırmalarda etik ilkelere uyulmayan çalışmaların bilimsel anlamda da geçerli olamayacağ 1 , bu bağlamda etik kurul onayı ve etik standartlara bağlı kalınması gereği şeklindedir (7).

Özelleşmiş 16 alt başlık ise genel olarak burada ifade edilmiş olan etik standartların hem genişletilmiş hem de özel olgulara uygulanmış formlarıdır. $\mathrm{Bu}$ başlıklar ise: Ötanazi, işkence, ölüm cezası, cinsiyet seçilimi, organ transplantasyonu, psikiyatristlerin medyadaki konuşmaları, psikiyatristin ayrımcılık ve etnik-kültürel konulardaki tutumu, psikiyatristin genetik araştırma ve danışmanlıklardaki yeri, tıpta psikoterapi etiği, endüstri ile ilişkiler ve çıkar çatışmaları, üçüncü taraflarla ortaya çıkan sorunlar, psikiyatrist ve hasta arasındaki güven ilişsisi ve klinik sınırların ihlali, psikiyatristlerin haklarının korunması, Alzheimer ve diğer demans tanılarının açıklanması, psikiyatristin ikili sorumluluğu (özellikle yasal-mahkeme süreçleri bağlamında), hastalar ve bakım verenlerle çalışma şeklindedir (7).

\section{Türkiye Psikiyatri Derneği (Tpd) Ruh Hekimliği (Psikiyatri) Meslek Etiği Kuralları ve Ruh Sağlığı Yasası Taslağı}

Ruh Hekimliği (Psikiyatri) Meslek Etiği Kuralları, 22 Haziran 2002 tarihinde TPD'nin I. Olağanüstü Genel Kurulu'nca kabul edilmiştir. Psikiyatrinin tıbbın önemli bir parçası olduğu ve tıp etiğinin genel etik ilkelerine uyulması gereği vurgulanmıştır. $\mathrm{Bu}$ bağlamda tıp etiğinin genel etik ilkelerinden kopmamakla birlikte psikiyatrinin kendi dinamikleri açısından özel etik ilkelerinin olması gerektiği belirtilmiştir. Özellikle toplumsal, kültürel ve ulusal değişkenler düşünüldüğünde etik ilkelerin değişken olabilecek yapısının göz önünde bulundurulması ve sürekli gözden geçirilmesi gereğine değinilmiştir.

Ruh Hekimliği (Psikiyatri) Meslek Etiği Kuralları'nın oldukça kapsamlı olduğundan bahsetmek mümkündür. Kurallar, 8 bölüm ve 50 maddeden oluşmaktadır. Birinci bölümde amaç ve kapsama yer verilmiştir. İkinci bölümde genel ilkeler ve kurallar yer alırken özellikle psikiyatristin mesleki sorumluluklarının etik çerçevesi çizilmektedir. Üçüncü bölümde ise hasta hakları ve hastahekim ilişkisi ele alınmıştır. Bu bölümde yer alan 17. madde özel olarak istem dişı yatış konusunun etik yönüyle ilişkilidir. $\mathrm{Bu}$ bağlamda istem dışı yatış durumunda tıbbipsikiyatrik gerekçenin ortaya çıkması ile hekimlik bilgisi ve vicdani sorumluluğun birlikteliğine değinilmektedir. Özellikle yasalara uygunluk ile birlikte insan hakları ve onuruna özen gösterilmesi gerektiği de vurgulanmıştır. Kuralların dördüncü bölümünü meslektaşlar arası ilişkiler oluştururken; beşinci bölümde insan haklarına ilişkin konular kapsanmış ve uluslararası ilkelere uyma, işkenceye yardım etmeme, ölüm cezası uygulamasına katılmama, tutuklu ve yükümlüler ile ilişkiler ile olağanüstü durumlarda psikiyatristin konumu ele alınmıştır. Altıncı bölüm araştırma ve yayın etiği konusuna ayrılmıştır. Yedinci bölüm de çeşitli hükümler başlığı altında ara durumlarda dayanak olabilecek tüzük ve metinlere değinilmektedir. Sekizinci ve son bölümde ise kuralların değiştirilme ve uygulanma esasları yer almaktadır (2).

Ruh Sağlı̆̆1 Yasası Taslağ1, 6 bölüm ve 22 maddeden oluşmaktadır. Taslağın ilk iki maddesi oldukça kapsamlı olarak amaç ve kapsam konularına ayrılmıştır. Ruh sağlığının geliştirilmesi ve sürdürülmesi için standartların belirlenmesi ve en iyi tedavi ve rehabilitasyon olanaklarının sağlanması ile mümkün olan en az kısıtlayıcı yöntemlerin kullanılması gibi konular öncelenmektedir. 3 . maddede ise yasa taslağında yer alan kavramlara ilişkin ayrıntılı bir tanımlama çabası mevcuttur. Örneğin; istemsiz yatış ve zorunlu yatış ve/veya tedavi kavramlarına bu madde içinde ayrı ayrı yer verilmiştir. 
İstemsiz yatış için; "Bir çocuk, ergen ya da erişkin ruh sağlığı ve hastalıkları uzmanının muayenesi sonrası gerekli görmesiyle, yakın zamanda ruhsal hastalığa bağlı risk potansiyelinin olduğu ve başka tedavi olanaklarının olmadığı bir durumda hastanın istemi dışında, çocuk ve ergenlerde kendisinin ve/veya yasal temsilcinin istemi dışında bir psikiyatri kliniğine yatırılmasıdır." ifadesine yer verilmiştir (8). Zorunlu yatış ve/veya tedavi için ise; "Ruh sağlığı yasası dışındaki yasalar gereği ya da ruhsal hastalığa bağlı kendine ya da başkalarına zarar verme ve/veya zarar görme riski olduğunda, hem kişinin tedavisini, hem de kişinin ve toplumun güvenliğini sağlamak amacıyla, risk halinin ortadan kalkmasına ya da önemli ölçüde azalmasına dek kişinin kendisinin ve yasal vasisinin rizasının olup olmamasina bakılmaksızın mahkeme kararıyla yatırılması ve/veya tedavi edilmesidir." ifadesi kullanılmıştır. Taslağın 15 ve 16 . maddeleri ise özel olarak istemsiz tedavi ve yatış ile istemsiz yatışta karar ve denetleme mekanizmaları konularına ayrılmıştır. $\mathrm{Bu}$ bağlamda oldukça ayrıntılı bir içeriğin taslakta yer aldığını söylemek mümkündür (8).

\section{Avrupa Konseyi Biyoetik Komitesi'nin Psikiyatriye İlişkin Ek Protokol Taslağı}

Avrupa Konseyi'nin İnsan Hakları ve Biyotıp Sözleşmesi biyoetik alanında uluslararası hukuk ve politikalar anlamında en önemli metinlerden biri olarak kabul edilmektedir (9). 1997'de kabul edilen Sözleşme, özellikle hasta hakları ve araştırmalara katılımcı olarak dahil edilen bireylerin hakları ile genetik ve embriyo çalışmaları gibi güncel etik tartışmaları ele alarak temel bir çerçeve çizmeyi amaçlamıştır (10). Ülkemiz tarafindan 3 Aralık 2003 tarih ve 5013 sayılı kanun ile söz konusu Sözleşme uygun bulunmuş ve 16 Mart 2004 tarihinde onaylanmıştır (11). Anayasa'nın milletlerarası antlaşmaları uygun bulmasını düzenleyen 90 . maddesince de iç hukuktaki yerini almıştır. Sözleşme'nin en önemli özelliklerinden birisi, dinamik bir yapıya sahip olmasıdır. Bu dinamik yap1 ise ek protokoller yoluyla Sözleşme'nin geliştirilmesi ve desteklenmesi sayesinde sağlanmaktadır (12). İnsan Hakları ve Biyotıp Sözleşmesi'nin 7. maddesi, ruhsal rahatsızlığı bulunan bireylerin korunması konusunu içermektedir. Ancak süreç içerisinde Sözleşme'nin dinamik yapısına uygun olarak ruhsal rahatsızlığ 1 olan bireyler ve psikiyatrik tedavilere ilişkin ek protokol oluşturulması konusu gündeme gelmiştir.

$\mathrm{Bu}$ sürece k1saca bakılacak olursa; ruhsal rahatsızlığ 1 olan bireylerin haklarının ve onurlarının korunması konusu, 2004 yılından itibaren, Avrupa Konseyi için önemli bir gündem maddesi olmuş ve aynı yıl yapılan Bakanlar Komitesi toplantısında bu konu ile ilgili bir tavsiye kararı yayımlanmıştır (3). Bu kararda, istem dışı yatış veya istem dışı tedavi; (i) içinde bulunduğu durumu anlayan ve sonuçları düşünebilen, onam verme kapasitesine sahip olup reddeden bireye; (ii) içinde bulunduğu durumu tam olarak kavrayamayan ve sonuçları öngöremeyen, onam verme kapasitesine sahip olmayıp karşı çıkan bireye uygulanan yatış veya tedavi olarak tanımlanmıştır (13). Bu tavsiye kararı üzerine çeşitli çalışmalar yapılmış ve üye ülkelerin yasal düzenlemelerinde, özellikle istem dışı yatış ve istem dışı tedavi gibi konularda, çeşitli boşluklar bulunduğu görülmüştür. $\mathrm{Bu}$ bağlamda, kişileri ve kişilerin haklarını koruyacak referansların oluşturulması, önemli bir gereklilik olarak değerlendirilmiştir ve İnsan Hakları ve Biyotıp Sözleşmesi'ne ek bir protokolün hazırlanması uygun görülmüştür (3).

Biyoetik Yönlendirme Komitesi'nin 2011 yılında gerçekleştirilen 40. Genel Kurul toplantısında, 2013 yılı programı için ruhsal rahatsızlıklara sahip bireylerin hak ve onurlarının korunmasını içeren ek bir protokolün düzenlenmesi üzerinde uzlaşılmıştır. Ek Protokol ile İnsan Hakları ve Biyotıp Sözleşmesi'nin akıl hastalığı bulunan kişilerin korunmasını içeren 7. maddesi ile Avrupa İnsan Hakları Sözleşmesi'nin 5/1-e maddesi hükümlerinin geliştirilmesi hedeflenmektedir. Ek Protokol'ün asıl amac1 ise olası istisnai ve uç durumları dikkate alarak, insan haklarının ve özerkliğin gözetilmesini garanti altına almaktır. Ek Protokol'ün hazırlanmasına ilişkin çalışmaların referans metinlerini, İnsan Hakları ve Biyotıp Sözleşmesi ve Avrupa İnsan Hakları Sözleşmesi ile bu Sözleşmelerin Avrupa İnsan Hakları Mahkemesi tarafindan 
verilen kararları oluşturmaktadır. Bununla birlikte, Birleşmiş Milletler Engellilerin Haklarına İlişkin Sözleşme (2006) başta olmak üzere, diğer uluslararası sözleşmeler de dikkate alınmıştır (3).

Ruhsal Rahatsızlığı Olan Bireylerin İstem Dışı Yatış ve İstem Dışı Tedavisine İlişkin İnsan Hakları ve Onurunun Korunması Hakkında Ek Protokol ilk olarak, Biyoetik Komisyonu tarafindan bir ön taslak geliştirilmesi şeklinde hazırlanmış; bu bağlamda 11 Mart 2014 tarihinde bu konuya ilişkin, hastalar ve hastaların aileleri, hekimler ve konuya ilişkin diğer sağlık çalışanları, insan hakları, hasta hakları ve ruhsal sorunu olan hastaları savunan gruplar gibi farklı alanlardan temsilcilerin katıldığı bir toplantı gerçekleştirilmiştir. Biyoetik Komisyonu, 22 Haziran 2015 - 15 Kasım 2015 tarihleri arasında, Ek Protokol taslağının üzerinde çalışılabilmesi ve konuya duyarlı farklı grupların yorumlarının ve görüşlerinin hazırlık sürecine yansıması amacıyla taslağın geniş kesimler için de ulaşılabilir kılmaya karar vermiştir (3). 22 Nisan 2016 tarihinde Avrupa Konseyi Parlamenter Meclisi'nde 2091 numaralı tavsiye kararı kabul edilmiş ve bu kararda Ek Protokol'ün taslağına ilişkin birtakım endişeler dile getirilmiştir. Hazırlanan taslağın Birleşmiş Milletler Engellilerin Haklarına İlişkin Sözleşme'nin maddeleri ile uyumlu olması ve hazırlanma sürecine engelli hakları örgütlerinin de dahil edilmesi gerektiği vurgulanmıştır. Bununla beraber, istem dışı tedavi sürecinde alternatif yöntemlere dikkat çekilmesi ve mümkün olduğu ölçüde bireylerin kararlarının sürece yansitılmas1 yönünde tavsiyelerde bulunulmuştur (14).

9 Kasım 2016 tarihinde gerçekleştirilen Avrupa Konseyi Genel Kurulu'nda Bakanlar Komitesi tarafindan, Biyoetik Komitesi, İnsan Hakları Yönlendirme Komitesi (CDDH) ve Engellilerin Haklarına İlişkin Ad-hoc Komite'nin (Ad-hoc Committee of Experts on the Rights of Persons with Disabilities) yorumlarını da göz önünde bulundurularak Parlamenter Meclisi'ne bir cevap kararı oluşturulmuştur (15). Karar'da taslak Ek Protokol'e ilişkin olarak, Birleşmiş Milletler Engellilerin Haklarına İlişkin Sözleşme'nin ruhuna uygun bir sürecin yürütülmesi, ülkelerin bu konuda benzer uygulamaları kullanmaya cesaretlendirilmesi ve hastaların istemli yatış veya istemli tedavi süreçlerine katılımları konusu üzerine katkıda bulunulması konularına değinilmiştir. Bununla birlikte, Bakanlar Komitesi, Biyoetik Komisyonu'na engellilik hakları ile ilgili örgütlerin sürece katılımına teşvik etmesini önermiştir (15).

Taslak metnin gözden geçirilmesinden ve kamuoyu görüşünün de alınmasından sonra, Biyoetik Komitesi 23-25 May1s 2018 tarihlerinde yapilan 13. Genel Kurul toplantısında taslak Ek Protokolünü ve buna ilişkin gerekçesini Avrupa İnsan Hakları Yönlendirme Komitesi'ne (CDDH), Avrupa İşkenceyi Önleme Komitesi'ne (CPT), Parlamenter Meclisi'ne, İnsan Hakları Komiseri'ne, Sivil Toplum Kuruluşları Konferansı'na ve Suç Sorunları Avrupa Komitesi'ne (CDPC) görüş almak amaciyla gönderme kararı almıştır (3). Biyoetik Komitesi'nin 1 Ocak 2020-31 Aralık 2021 tarihleri arasındaki çalışma takviminde taslak metnin son halinin verilmesi kararlaştırılmıştır (16).

\section{Ek Protokol'ün İçeriği}

Mevcut hali 8 bölüm ve 23 maddeden oluşan Ek Protokol'de istemsiz yatı̧s ve tedavi kavramlarının, bunlara konu olan kişilerin durumunun, istemsiz yatı̧̧ sürecinde değerlendirici olarak hekimler ve yetkinlikleri gibi konularının ele alındığı görülmektedir. Genel hatları ile protokol bölümleri ve bölümlerin içerikleri şu şekildedir (17):

1. Bölüm; amaç ve kapsama ayrılmıştır. Ek Protokol'ün temel amacinın, gerekli durumlarda başvurulacak istem dışı yatış ve tedavi olgularında insan onurunun, kişiliğinin ve haklarının korunmasının olduğu ifade edilmektedir. Yine bu bölümde Ek Protokolde yer alan kavramlara açıklık getirilmektedir.

2. Bölüm; alternatif tedbirlere/önlemelere ayrılmıştır. İstem dışı tedavi ya da yatış sürecine başvurulmadan önce daha az sınırlayıcı yöntemlere ilişkin gösterilmesi gereken çabaya atıf yapılmaktadır. 
3. Bölüm; genel hükümlere ayrılmıştır. İstem dışı yatış ve tedavi sürecinin iç hukuka uygun olması gereği, uygun ve gereklilik hallerinin oluşması gibi durumlarda başvurulacak bir yöntem oluşundan bahsedilmektedir. Ayrıca istem dişı yatış veya tedaviye konu olan bireyin yasal haklarının güvence altına alınması bağlamında yasal bir temsilcisi ya da güvenilir bir tanıdığının olması gibi konular ele alınmıştır. $\mathrm{Bu}$ başlıkta süreçte değerlendirici pozisyonda olan bireylerin yetkinlikleri ile tanısal olarak istem dışı yatış ve tedaviye ilişkin tıbbi bilginin uluslararası standartlar ve bilimsel bilgiyle uyumluluğu konusuna da yer verilmiştir. Yani tedavi edici ve bakım verici pozisyonda olan bireylerin gerekli mesleki yetkinlik ve deneyime sahip olmalarına atıf yapılmaktadır. Bu başlıkta ayrıca ek protokole taraf olan ülkelerin istem dışı yatış ve tedavi bağlamında uygun koşulara sahip alt yapıyı planlamaları istenmektedir.

4. Bölüm; istem dişı yatış ve tedavi kriterlerine ayrılmıştır. "Kişinin ruhsal sağlığ sağlığına yönelmiş zarar verme riskinin ortaya çıkması ve kişinin yatış konusundaki karar yetisinin ciddi biçimde zarar görmesi; kişinin ruhsal sağlığının ötekilere yönelmiş ciddi zarar verme riski taşıması; yatışın terapötik bir amaçla ve; mevcut istemli tedbir olanaklarının bahsedilen riskleri azaltmak için yeterli olmaması" şeklindeki durumlar istem dışı yatış kriterlerini oluşturmaktadır. "Kişinin ruhsal sağlığı nedeniyle kendi sağlığına yönelmiş zarar verme riskinin ortaya çıkması ve kişinin tedavisi konusundaki karar yetisinin ciddi biçimde zarar görmesi; kişinin ruhsal sağlığının ötekilere yönelmiş ciddi zarar verme riski taşıması; tedavinin terapötik bir amaçla ve; mevcut istemli tedbir olanaklarının bahsedilen riskleri azaltmak için yeterli olmaması" ise istem dişı tedavi kriterlerini oluşturmaktadır.

5. Bölüm; istem dışı yatış ve tedaviye ilişkin prosedürleri içermektedir. Bu bölümde istem dışı yatış ve tedavi kararına ilişkin standart prosedürler, acil durumlardaki prosedürler, istem dışı yatış veya tedavi sürecinin kapsamının uzatılmasi ve sonlandırılması ve tüm bu süreçlerin hukukla olan ilişkisi ele alınmıştır. $\mathrm{Bu}$ başlık altında istem dışı yatış ve tedavi kararının en az bir yetkin ve deneyimli hekimin uygun değerlendirmesine dayanması gerektiği belirtilmektedir. Standart süreçte zorunlu yatış ve tedavi kararı bir mahkeme kararı ya da yasal olarak yetkili bir kurumun kararına dayanmalıdır ve bu karar "daha önce referans verilen tıbbi bir değerlendirmeye, istem dışı yatış ve tedavi kriterlerine uygunluğa, yine uygun yasal temsilcisi veya güvendiği kişi varsa onların bilgilendirilmesine, yatışına veya tedavisine karar verilen bireyin öncesinde gerçekleştirdiği bir isteği veya koyduğu bir çekincesi varsa" bunların dikkate alınmasına dayanmalıdır. Gerekli durumlarda en az iki hekimin değerlendirmesi de uygun olabilir ki, bu durumda "bu hekimlerden birisi hastanın primer bakım sürecinde yer almayan biri olmalıdır" şeklinde bir değerlendirmeye de yer verilmiştir. $\mathrm{Bu}$ tür hukuksal bir süreci olanaklı k1lmayan acil durumlarda ise: İstem dışı yatış veya tedavi kararı, daha önce sayılan koşullara uygun olmak kaydiyla, yalnızca uygun tıbbi değerlendirmeye bağlı olarak gerçekleşebilir denilmektedir. İstem dışı yatış ve tedavi sürelerine ilişkin olarak yasal düzenlemeler gerçekçi olarak ve periyodik değerlendirmeleri de içerecek şekilde düzenlenmelidir. İstem dışı yatış veya tedavi sürecinin sonlandırılması, başka bir yasal sonlandırma kararı süreci devreye girmediyse, kriterlerin ortadan kalkmasına dayanır ve bu konuda sorumlu karar verici otorite, kişinin 
hekimi ya da mahkeme tarafindan atanmış hekimidir. Tüm bu süreçte istem dışı yatışı olan ya da tedavi edilen bireyin bireysel haklarını işletebilmesi desteklenmeli, yasal temsilcisi ya da güvendiği kişilerce desteklenmesi sağlanmaya çalışılmalıdır. Yine kişi ve yakınlarının mahkemeye başvurma haklarının olduğunun bilinmesi ve bu konuda kişilere bilgi verilmesi gerektiği konusuna değinilmiştir. Ancak böyle bir durumda mahkemelerin ivedilikle karar vermesi gerektiğine de vurgu yapılmıştır.

6. Bölüm; özel durumlar başlığını taşımaktadır. Bu bölümde izolasyon ve kısıtlama seçenekleri ele alınmıştır. Ayrıca geri dönüşümsüz biçimde zarar verebilecek tedavi seçeneklerine başvurulamayacağ 1 da belirtilmiştir.

7. Bölüm; bilgi ve iletişim başlı̆̆ını taşımaktadır. Hastaların bilgi edinme ve iletişim haklarına değinilmektedir. Hasta tedavi ve yatış konusunda ve verilen ilaçlar konusunda bilgilendirilmelidir. Yine yasal temsilcisi veya güvenilen kişiler de sürece, karar değişikliklerine, yatış veya tedavi sürecinin uzamasına ve kriterlere ilişkin bilgilendirilmelidir. $\mathrm{Bu}$ bilgilendirmelerin yapıldı $\breve{g}_{1} \mathrm{da}$ belgelenmeli ve gerekirse bu bilgilendirmenin yapıldığ 1 konusu mahkemelere de sunulabilir olmalıdır. Kısıtlama veya izolasyon yapıldığında da ilgili bireyler bilgilendirilmelidir. Hastanın diğer bireylerle iletişimi ancak sağlığına veya diğer kişilere yönelik bir risk taşıyorsa k1sitlanabilir.

8. Bölüm; kayıt tutma, şikayet süreci ve monitörizasyon hakkındadır. İstem dışı yatış ve tedavi sürecine giren hastaların ayrıntılı ve kapsamlı tıbbi kayıtları tutulmalıdır. $\mathrm{Bu}$ verilere kimlerin erişebileceği ve ne kadar süreyle saklı tutulacakları konusu yasayla belirlenmelidir. Hasta veya yakınlarının sürece ilişkin işletilebilir şikayet mekanizmalarına ulaşabilir olmaları gerekmektedir. Son olarak, hazırlanan ek protokolün uygun bir şekilde işleyip işlemediği bağımsız bir taraf tarafindan değerlendirilmeye açık olmalıdır.

\section{Tartışma}

Ek Protokol'ün oluşturulma gerekçeleri içinde yer alan "bazı ülkelerdeki yasal düzenlemelerdeki boşluklar" önemli bir tartışma konusu olduğu gibi, Ek Protokol ülkemizde konuya ilişkin olarak ruh sağlığı çalışanlarının beklenti ve çalışmalarının gerçekçi doğasını yansıtmaktadır. Ülkemizde henüz yasalaşmamış olsa da TPD'nin önemli düzeyde katkı sunduğu "Ruh Sağlığı Yasa Taslağı" ile "Ruh Hekimliği (Psikiyatri) Meslek Etiği Kuralları" içerisinde konunun ayrıntılı biçimde yer almış olduğu dikkate değerdir $(2,8)$.

Karşılaştırma yapmak gerekirse TPD'nin meslek etiği kurallarının oldukça kapsayıcı olduğunu ifade etmek mümkündür. $\mathrm{Bu}$ bağlamda meslek etiği kurallarının 4 . maddesinin ilkesel olarak konuya ilişkin olarak tüm çekinceleri gözettiğini söylemek mümkündür. Yine etik kuralların 17. maddesi istem dişı yatış ve tedavi konusuna ayrılmıştır, madde genel olarak ek protokol ile uyumlu ve adeta protokolü özetler niteliktedir. 30 . madde ise insan haklarına saygı konusuna ayrılmış ve bu maddede insan onuru ve kişiliğinin öncelenmesi ve gereklilik hallerinde mümkünse en az kısıtlayıc1 tedavilerin uygulanmasına atıf yapılmıştır (2).

Ruh Sağlı̆̆ı Yasa Taslağı, taslak kapsamlı bir metin olma özelliğine sahiptir ve ek protokole benzer bir biçimde taslakta yer alan kavramlar ayrıntılı şekilde açıklanmıştır. İstem dışı tedavi ve yatış kavramlarına ek olarak zorunlu yatış ve tedavi kavramlarına yer verilmiştir. $\mathrm{Bu}$ bağlamda, kavramsal açıklığın daha net olduğu ifade edilebilir. Bu tür bir kavramsal çerçevenin protokolde acil durumlar ve normal süreç şeklinde yer aldığ görülmektedir (8).

Ruh Sağlığı Yasa Taslağı'nda 15, 16 ve 17. maddeler ayrıca zorla yatış konusuna ayrılmıştır. Yasa taslağında konu üç madde ile sınırlı olmakla birlikte, alt başlıkları ile düşünüldüğünde oldukça kapsayıcı ve açıklayıcı nitelikte olduğu söylenebilir. Taslak metinde, Ek Protokol'de yer alan tüm ifade ve 
başlıkların kapsandığını görmek mümkündür, ayrıca hukuki haklar konusunda bilgilendirme ve hastaya temsilci vb. kişilerin atanması konularına kapsamlı açıklamalar getirilmiştir. Bununla beraber, Ek Protokol'de açık birakılan mahkemelere bildirim ve bilgilendirme zamanları ile bir defada istenebilecek en uzun istemsiz yatış süreleri ile bu sürelerin uzatılması gibi konular yasa taslağında ayrıntılı bir biçimde ele alınmıştır (8). Tip kurumunun sorumlulukları ile hukuk kurumunun yetki ve sorumlulukları ayrintılı bir biçimde ele alınmıştır. Bu farklılığın ek protokolün bir ilke metni olması ve yasa taslağının ise iç hukuk için bağlayıcı ve işe vuruk olmasıyla açıklanabilir.

İnsan Hakları ve Biyotıp Sözleşmesi içinde yer alan kişinin kendi sağlığına yönelik ciddi risklerin varlığında onam alınmama konusunun ek protokolde diğer kişilerin iyiliğine yönelmiş bir risk için de genişletilmiş olduğu söylenebilir ki; bu gerek hukuk alanının gerekse de tıp kurumunun toplumsal sorumluluğuna işaret etmektedir $(11,17)$. Ek Protokol'ün kabul edilmesi ve ülkemiz iç hukukunda da onaylanması halinde; gerek zorla yatış ve tedavinin yasal zeminin açıklığa kavuşması gerekse de ruh sağlığı çalışanlarının meslek sınırlarının netleşmesi açısından olumlu katkıları olacağını söylemek mümkündür.

\section{Sonuç}

Ek Protokol, kabul edilmesi halinde ülkemiz iç hukukunu etkileme potansiyeli taşımaktadır. Dolayısıyla protokole ilişskin ilkesel duyarlılık önemli bir gereksinimdir. Ancak yapılan değerlendirmede ülkemiz ruh sağlığı profesyonellerinin ortaya koydukları metinlerin de oldukça kapsayıcı oldukları ve uygulanabildikleri takdirde pek çok etik sorunun aşılacağı sonucuna varılmıştır. $\mathrm{Bu}$ bağlamda, eksikliği dillendirilen Ruh Sağlığı Yasası'nın çıkmasının da önemli bir gereksinim olduğunu ve pek çok pratik sorunun çözümünde yararlı olabileceği düşünülmüştür.

Bu makale 23-27 Ekim 2019 tarihleri arasinda İstanbul'da gerçekleştirilen 55. Ulusal Psikiyatri Kongresi'nde sunulan "Avrupa Konseyi Biyoetik Komitesi'nin Psikiyatriye İlişkin Ek Protokolü Neler Söylüyor?" başlıkl poster sunumuna dayanmaktadir.

\section{KAYNAKLAR}

1. Uluğ B. Türkiye Psikiyatri Derneği 6. Olağan Genel Kurulu'na Doğru, Türkiye Psikiyatr Derneği Bülteni. 2005;8:3.

2. Türkiye Psikiyatri Derneği. Ruh Hekimliği (Psikiyatri) Meslek Etiği Kuralları. https://www.psikiyatri.org.tr/tpd-

kutuphanesi/belge/311. Erişim tarihi: 03 Eylül 2020.

3. Council of Europe. About Psychiatry. https://www.coe.int/en/web/bioethics/psychiatry/a bout. Erişim tarihi: 19 Mart 2019.

4. Helmechen H, Okasha A. From the Hawaii Declaration to the Declaration of Madrid. Acta Psychiatr Scand. 2000;101:20-23.

5. Steenfeldt-Foss OW. Ethical Principles in Psychiatry: The Declarations of Hawaii and Madrid. In: Helmchen H, Sartorius N, editors. Ethics in Psychiatry: European Contributions. Dordrecht: Springer; 2010. p. 129-137.

6. World Psychiatric Association. Declaration of Hawaii. J Med Ethics. 1978;4:71-3.

7. World Psychiatric Association. Declaration of Madrid. 2011.

8. Ruh Sağlı̆̆1 $\quad$ Yasa Taslağı. https://www.psikiyatri.org.tr/uploadFiles/2811201 717434-Ruh-Sagligi-Yasa-Taslagi.pdf. Erişim tarihi: 3 Eylül 2020.

9. Hottois G. A Philosophical and Critical Analysis of the European Convention of Bioethics. J Med Philos. 2000;25:133-46.

10. Callard F. Between Legislation and Bioethics: The European Convention on Human Rights and Biomedicine. In: Helmechen $\mathrm{H}$, Sartorius N, editors. Ethics in Psychiatry: European Contributions. Dordrecht: Springer; 2010. p. 7396.

11. Biyoloji ve Tibbın Uygulanması Bakımından İnsan Hakları ve İnsan Haysiyetini Korunması Sözleşmesi: İnsan Hakları ve Biyotıp Sözleşmesinin Onaylanmasının Uygun Bulunduğuna Dair Kanun. Resmi Gazete; 2003.

12. Uerpmann-Wittzack R. The Council of Europe: Its Law and Policies. In: Schmahl S, Breuer M, editors. The Council of Europe: Its Law and Policies. Oxford: Oxford University Press; 2017. p. $572-88$. 
13. Committee of Ministers. Recommendation No. $\operatorname{Rec}(2004) 10$ of the Committee of Ministers to Member States concerning the Protection of the Human Rights and Dignity of Persons with Mental Disorder. Strazburg; 2004.

14. Parliamentary Assembly of the Council of Europe. The Case Against a Council of Europe Legal Instrument on Involuntary Measures in Psychiatry. Strazburg; 2016

15. Committee of Ministers. "The Case Against a Council of Europe Legal Instrument on Involuntary Measures in Psychiatry" Parliamentary Assembly Recommendation 2091 (2016) Reply of the Committee of Ministers. Strazburg; 2016.

16. Committee on Bioethics (DH-BIO) 16th meeting 19-21 November 2019. Strasbourg; 2019.

17. Council of Europe. Draft Additional Protocol Concerning the Protection of Human Rights and Dignity of Persons with Mental Disorder with regard to Involuntary Placement and Involuntary Treatment (DH-BIO/INF (2018) 7). Strazburg. 2018 .

๑Copyright 2021 by Osmangazi Tıp Dergisi - Available online at tip.ogu.edu.tr @Telif Hakkı 2021 ESOGÜ Tıp Fakültesi - Makale metnine dergipark.org.tr/otd web sayfasından ulaşılabilir. 